\title{
Orgulho e preconceito: a "objetividade" como mediadora entre o jornalismo e seu público
}

\begin{tabular}{c}
\hline \hline Flávia Biroli \\
Instituto de Ciência Política \\
Universidade de Brasília \\
Luis Felipe Miguel \\
Instituto de Ciência Política \\
Universidade de Brasília \\
\hline \hline
\end{tabular}

\begin{abstract}
Resumo: $\mathrm{O}$ artigo discute o valor da "objetividade" na construção do discurso e na orientação das práticas jornalísticas. A análise de revistas brasileiras semanais de informação permite observar que o ideal da objetividade e a afirmação dos valores morais não são excludentes: "fatos objetivos" e julgamentos complementam-se na legitimação do jornalismo como guardião dos valores sociais. O compartilhamento de posições sociais - e preconceitos - entre os jornalistas e seu público permite que perspectivas e interesses específicos sejam vocalizados como se correspondessem à totalidade, naturalizando um padrão de valores e transmutando julgamentos em fatos. No jornalismo, a neutralidade corresponde à validação de discursos hegemônicos.
\end{abstract}

Palavras-chave: jornalismo; objetividade; perspectivas sociais; interesses; política

\begin{abstract}
The article discusses the value of "objectivity" for journalistic discourses and practices. The analysis of Brazilian weekly news magazines confirms the comprehension that the ideal of objectivity and the assertion of moral values do not exclude each other: "objective facts" and judgments are complementary in legitimating journalism as the guardian of social values. The sharing of social positions - and prejudgments - between journalists and their public allows specific perspectives and interests to be voiced as if they equal the totality, naturalizing a pattern of values and making judgments into facts. In journalism, neutrality corresponds to the validation of hegemonic discourses.
\end{abstract}

Keywords: journalism; objectivity; social perspectives; interests; politics 
- Yo creía que los periodistas lo inventaban todo, sin necesidad de comprobar los hechos.

AIRA, C. Las aventuras de Barbaverde

O valor da "objetividade" confere legitimidade ao jornalismo, diferenciando-o de outros discursos e práticas sociais. Em torno dele, organizam-se a ética que define o jornalismo como profissão e as práticas rotineiras que estabelecem as diferenças entre o bom e o mau jornalismo. Para o público, o registro competente da verdade pelos jornalistas depende de sua capacidade de tomar contato com a realidade sem os vieses que a falta de conhecimento apropriado, de um lado, e o interesse e a parcialidade, de outro, imporiam à ampla maioria dos indivíduos.

No mundo moderno, o ideal da objetividade corresponde, grosso modo, à valorização do acesso a uma verdade que estaria contida na realidade exterior e que seria independente dos processos cognitivos. No jornalismo, ele impõe, em primeiro lugar, um compromisso com a busca por esta verdade, que é de cada profissional e que é reforçado pelo controle mútuo e pelos códigos da deontologia jornalística. Também para o público, o bom jornalismo é aquele que sustenta esse compromisso, fornecendo informações confiáveis. Mas os obstáculos à objetividade não residem apenas na tentação - sempre presente - do falseamento deliberado dos fatos em benefício próprio. Sua outra face, mais insidiosa, são as condições concretas de construção da notícia, nas quais os relatos são indissociáveis da posição social dos jornalistas. O viés deixa, assim, de ser uma contingência.

É porque o envolvimento parcial com a realidade é inevitável que as técnicas que tornariam a objetividade possível correspondem a estratégias ou marcas de distanciamento. A objetividade envolve a valorização de práticas e habilidades que permitiriam que o acesso à realidade não fosse maculado pelos intermediários que o tornam possível. O reconhecimento de que os profissionais têm competência distinta para acessar - e esclarecer - a realidade exterior sobrepõe-se à desvalorização da singularidade e da posição social específica desses mesmos indivíduos. A valorização do discurso científico, sobretudo nas formas que assume a partir do século XIX, é fortemente marcada pela divisão entre iniciados e leigos, sendo os primeiros aqueles que adquirem domínio sobre os procedimentos, normas e saberes compartilhados que garantiriam a produção de discursos verdadeiros. Mas a neutralidade desses sujeitos é uma exigência para que seu discurso seja fiel à realidade, e só a ela. Em outras palavras, a objetividade exige a neutralização ou suspensão do sujeito para que a verdade se apresente.

No jornalismo, a conexão entre verdade e suspensão da perspectiva social do sujeito assume formas específicas. A partir das décadas iniciais do século XX, o preceito da objetividade passaria a ser central à cultura jornalística, constituindo a identidade dos jornalistas como profissionais e as formas de normatização e controle de suas práticas. Em geral, a fixação do ideal da objetividade tal como hoje entendido é creditada ao desenvolvimento da imprensa nos Estados Unidos - sobretudo à emergência do jornalismo comercial, sustentado por publicidade, e à introdução de inovações como o telégrafo e a fotografia, que ampliavam a possibilidade do fornecimento de "fatos" ao público e o colocavam diante de informações tidas como fragmentos incontestáveis do mundo real. As mudanças tecnológicas contribuíram para a fixação de um conjunto de normas com força moral, que conferia identidade a esse 
grupo ocupacional. Inovações técnicas, que proporcionam novas possibilidades de exercício profissional, e parâmetros normativos, que privilegiam algumas destas possibilidades, se realimentam. Como desdobramento deste processo, o ideal da objetividade teria firmado uma relação mais estreita com o jornalismo estadunidense do que com as práticas jornalísticas em outros lugares do mundo. Michael Schudson (2001) enfatiza a incompleta adesão de profissionais de outros países ao modelo normativo estadunidense. Seu foco é a comparação com o jornalismo europeu, especialmente o francês.

Em relação à América do Sul, é conhecida a análise de Silvio Waisbord, que entrevistou jornalistas de diversos países e concluiu que, mesmo com a incorporação das inovações tecnológicas que teriam propiciado o triunfo da norma nos Estados Unidos e o desenvolvimento de uma imprensa voltada ao mercado, persistia no subcontinente um amplo "ceticismo sobre a objetividade como o princípio basilar do jornalismo" (WAISBORD, 2000, p.124). No entanto, há diferença entre um discurso cético abstrato sobre a objetividade, efeito da disseminação de uma crítica acadêmica, e o papel concedido a ela nos esquemas efetivos de valoração da atividade profissional, internamente ao campo, e de legitimação dessa atividade diante do público. Ainda que existam diferenças entre as práticas jornalísticas de diferentes locais, o ideal da objetividade firmou-se como um valor central pelo mundo afora.

Analistas que se debruçaram sobre uma controvérsia concreta, em que personalidades da imprensa mobilizaram argumentos em defesa de sua prática e expressaram os critérios de hierarquização das reputações, sugeriram que "a objetividade tem um papel mais importante, ao menos entre os jornalistas brasileiros, do que aquele reconhecido por Waisbord" (ALBUQUERQUE e SOARES, 2004, p.158). Os primeiros manuais e compêndios de normas sistematizados no Brasil, nas décadas de 1930-50, apresentam a objetividade como um ideal que, ao mesmo tempo, disciplina, controla e confere legitimidade às práticas jornalísticas. A fidelidade aos fatos seria a marca do jornalista moderno e deveria orientar a reorganização das práticas jornalísticas, propiciada pelas inovações tecnológicas e pela produção da notícia em escalas industriais. A padronização das rotinas e a diferenciação entre os profissionais do jornalismo e aqueles que foram, a partir de então, vistos como literatos ou militantes políticos foi fortemente orientada pelo ideal da objetividade, que teria impacto para a definição das normas vigentes no campo décadas depois.

Os registros são variados mas, mesmo quando existe uma percepção de que a anulação do jornalista é impossível e indesejável, como no Manual de redação e estilo d'O Estado de S. Paulo, permanece a exigência de que os textos sejam "imparciais e objetivos", não expondo opiniões, mas fatos (OESP, 1990, p.18). Por vezes, o termo objetividade é descartado, mas fica mantida a oposição entre fatos e opiniões, como ilustram as palavras do jornalista Mino Carta: “Jornalismo é uma coisa séria, tem que ser praticado com seriedade. E seriedade não quer dizer objetividade, e sim honestidade. Ser honesto significa, antes de mais nada, respeitar a verdade factual com devoção canina" (ABREU, LATTMAN-WELTMAN e ROCHA, 2003, p.208).

Trata-se de um movimento central no entendimento do valor da objetividade após a crítica que demonstrou que o ideal, em toda sua extensão, é irrealizável. Se não é possível apagar a posição do narrador, que interfere no narrado com suas (inevitáveis) escolhas e ênfases, ao menos são banidos os 
julgamentos e restam, no discurso do jornalismo, nada além de fatos. Mesmo resultando de um processo de seleção, os fatos corresponderiam ainda assim àqueles fragmentos indiscutíveis da realidade, não contaminados por opiniões, sempre controversas e duvidosas, além de parciais e possivelmente autointeressadas.

A adesão ao ideal da objetividade não é, portanto, impermeável às críticas aos limites desse ideal. Mas, assimilada a crítica, a separação entre opinião e fato permanece como elemento crucial para a avaliação do "bom jornalismo". O jornalismo pode não sustentar mais que aquilo que ele apresenta a seu público é a realidade - mas garante que, ao menos, é realidade. De resto, o reconhecimento de que outros recortes da realidade são possíveis é inócuo, já que, dado seu poder de agenda, bem como a dependência cognitiva do público, o jornalismo tem curso social como espelho do mundo real e os próprios profissionais tendem a encarar suas escolhas como "óbvias". Outros recortes são possíveis, mas aquele que o jornalismo apresenta é o que se impõe como importante, tanto por seu impacto junto ao público quanto porque os jornalistas não vacilam na crença de que são dotados da capacidade de selecionar os fatos verdadeiramente dignos de relato.

Como ideal compartilhado, a objetividade se materializa também em orientações práticas que permitiriam rotinizar o trabalho, tipificando situações e eventos inesperados. Em seu estudo hoje clássico, Tuchman descreveu o que chamou de "rituais" da objetividade jornalística. Partindo da compreensão de que o valor da "objetividade" está no coração da legitimidade das práticas da imprensa, ela observou como, diante dos imperativos da produção industrial das notícias, a busca por um resultado tão exigente - colar o discurso no mundo real externo de tal forma que a intermediação do emissor fosse anulada ou suspensa - foi substituída por uma série de procedimentos padronizados, como ouvir os dois lados, usar criteriosamente as citações, etc. (TUCHMAN, 1972). Os procedimentos relatados por Tuchman não representam uma "traição" ao ideal da objetividade, que seria então substituído por um simulacro, mas sua adaptação aos imperativos da produção industrial da notícia.

A discussão realizada neste artigo não se prende, no entanto, à constatação da importância do ideal da objetividade para a deontologia desse campo profissional, para a definição do discurso e das rotinas jornalísticas. Entendemos a objetividade como um dispositivo que tem papel central na legitimação de discursos hegemônicos no jornalismo, na apresentação de julgamentos como fragmentos de realidade transpostos para o noticiário. O discurso jornalístico naturaliza um código de avaliação dos fenômenos que reporta. É o processo de "objetivação de padrões morais" (ETTEMA e GLASSER, 1998, p.71; ênfase retirada). Os discursos que organizam as categorias por meio das quais a realidade é apreendida e significada não aparecem enquanto tal, isto é, constituem pressupostos naturalizados sobre os quais um outro discurso, o do noticiário cotidiano, se constrói. Os primeiros ativam consensos previamente estabelecidos que permitem, por exemplo, que o caráter transgressor de determinados comportamentos seja tratado como "fato" inquestionável e desprovido de ambiguidades ${ }^{1}$. A condenação não se faz em nome de algum valor moral, mobilizado para julgar aquela situação - e que poderia ser objeto de análise e contestação; ela é apresentada como uma constatação empírica. O noticiário é

\footnotetext{
${ }^{1}$ Para uma análise deste processo tendo como caso o “mensalão" do primeiro governo Lula, ver Miguel e Coutinho (2007).
} 
verdadeiro, nesse sentido, em sua correspondência a concepções previamente cristalizadas. Os pressupostos sobre os quais o noticiário se constrói não são tematizados.

A sobreposição da objetividade à imparcialidade faz com que ganhem relevância simultaneamente, como ideais, a correspondência a uma realidade externa e sua apreensão de um ponto de vista não situado socialmente, que não contém perspectivas, simpatias, interesses. A parcialidade levaria a enviesar ou ocultar a verdade. A objetividade enquanto universalidade sustentaria um julgamento que corresponde à verdade de uma situação (BOUDANA, 2010).

Por isso, definimos a imparcialidade como uma sorte de universalismo. A fantasia de uma perspectiva não-situada socialmente, isto é, que transcende os conflitos sociais, é recorrente - do funcionalismo como "classe universal" em Hegel aos intelectuais mediadores de Karl Mannheim ou à "posição original" de John Rawls. O jornalismo a incorpora, de maneira tácita, em suas práticas. Ele se apresenta como capaz de determinar quais são as preocupações centrais da sociedade num determinado momento e quais as contribuições relevantes ao debate sobre elas. A capacidade de tomar tais decisões "objetivamente" implica em se colocar num ponto de vista que sobrevoa os interesses parciais em conflito. Idealmente, o jornalismo vocalizaria uma verdade autônoma em relação às disputas e conflitos.

A imparcialidade não é, portanto, a equidistância entre os lados, mas a capacidade de se apresentar como ocupando a posição do universal. E a neutralidade não é a ausência de valores, mas a naturalização de um padrão de valores que se transmuta de julgamento em fato ${ }^{2}$. Na qualidade de vinculação da narrativa ao mundo real, a objetividade é balizada por estes dois ideais complementares, que sustentam as pretensões de escolha não-enviesada dos fatos a serem reportados e de narrativa isenta e factual. O grau de adesão a esse conjunto de ideais determina a respeitabilidade dos órgãos e dos profissionais de imprensa, interna ao campo, e a credibilidade de suas informações, externa a ele.

Diante da importância atribuída à objetividade, é questionável como práticas jornalísticas que, aparentemente, se afastam dela de forma tão marcada permanecem influentes e respeitadas. No Brasil, o caso que mais chama a atenção é o de Veja, a revista semanal de informação da Editora Abril. Circulando desde 1968, hoje com uma tiragem superior a um milhão de exemplares, é uma das publicações mais influentes do país. A elite política está atenta a ela, que é indicada como uma das três revistas preferidas por mais de $70 \%$ dos deputados federais, muito acima de suas concorrentes (FSB COMUNICAÇÕES, 2009, p. 18). As classes médias, de onde brotam os chamados "formadores de opinião", têm em Veja uma de suas fontes mais importantes de informação. A passagem por sua redação é vista como uma experiência que valoriza o currículo profissional.

No entanto, Veja adota um estilo de jornalismo que rompe ostensivamente com os cânones da objetividade. Sua adjetivação é agressiva, suas antipatias são explícitas, sua predileção por determinados temas da agenda é indisfarçada - características que se acentuaram nos últimos anos. As personagens de suas matérias são tratadas com pesos e medidas bem diferenciados, conforme a posição que

\footnotetext{
2 Em muitos estudos sobre jornalismo, "neutralidade" significa "desatenção às implicações" das notícias, que seriam veiculadas sem preocupação com quem será prejudicado ou beneficiado por elas (cf. Gans, 2004 [1979], p. 183). Aqui a usamos no sentido de "neutralidade valorativa", próxima do Wertfreiheit weberiano.
} 
BIROLI, F.; MIGUEL, L. F. Orgulho e preconceito: a "objetividade" como mediadora...

possuem. Os muitos adversários da revista não se cansam de denunciar o "antijornalismo" que ela adota, muitas vezes apresentando evidências de contaminação do noticiário por interesses políticos, comerciais ou mesmo desavenças pessoais ${ }^{3}$. Mesmo assim, Veja permanece numa das posições centrais da imprensa brasileira.

Este "enigma" é o ponto de partida deste artigo. As três primeiras seções discutem a convivência entre o ideal da objetividade e discursos normativos, constituídos por valores e julgamentos próprios. Sustentam que enquadramentos morais e, como tais, valorativos, são a base do noticiário, mesmo quando ele cumpre os rituais da objetividade, como o recurso equilibrado e ponderado às fontes. O compartilhamento desses enquadramentos entre os jornalistas, e entre os jornalistas e seu público, faz com que sejam tomados como um quadro neutro de referências. A quarta seção se debruça sobre a atuação de Veja em alguns episódios do noticiário recente, mostrando como a revista se distancia da roupagem ostensiva da objetividade, sem que perca a legitimidade diante de seu público. A conclusão, por fim, sumariza os resultados da análise, reforçando a relação entre objetividade, legitimidade e compartilhamentos de valores.

\section{0 espelho fiel}

A compreensão do jornalismo como um conjunto de procedimentos capaz de produzir um espelho fiel à realidade "externa" já foi objeto de muitas críticas e pode ser vista como uma posição ingênua. A objetividade se mantém, no entanto, como um valor que permite avaliar as práticas jornalísticas e o desempenho dos profissionais. Além disso, a correspondência entre o produto jornalístico e os procedimentos e marcas textuais que funcionam como índices de objetividade é um dos pilares de sustentação da confiabilidade de um veículo. É como um ideal, e não como uma realidade de fato, que a objetividade orientaria as práticas jornalísticas. Mas esse ideal organiza concretamente as relações e valores internos ao campo, assim como sua legitimidade externa.

A objetividade pode ser, assim, entendida como um valor que referencia a prática jornalística profissional contemporânea, constituindo as clivagens entre o bom jornalismo e o jornalismo ruim (CARPENTIER e TRIOEN, 2010). Como ideologia ocupacional (DEUZE, 2005), ponto nodal dos valores e da identidade dos jornalistas (CARPENTIER, 2005), seria fundamental para avaliar a competência e o apego a normas éticas compartilhadas dos profissionais, garantindo a legitimidade de suas práticas diante do público e balizando a defesa de procedimentos e referenciais éticos que orientam a rotina de produção e definem a identidade dos profissionais diante das pressões dos proprietários das empresas, de suas fontes ou do Estado. O fato de que esse valor seja mobilizado de formas variadas e esteja relacionado a procedimentos e estratégias heterogêneas não parece reduzir seu peso na avaliação das práticas cotidianas e da competência e rigor ético dos profissionais (BOUDANA, 2010).

A objetividade cumpre, assim, uma função estratégica na conquista de autonomia para o campo jornalístico. Um campo é um "microcosmo" dotado de "seu próprio nomos", como afirma

\footnotetext{
${ }^{3}$ O exemplo mais conhecido é o "dossiê" publicado na internet, no começo de 2008, pelo jornalista Luís Nassif. Disponível em: <luis.nassif.googlepages.com>. Acesso em: nov. 2009.
} 
Bourdieu (2005 [1995], p. 33). Ao tomar o lugar deste nomos, tornando-se o "código moral" do jornalismo, nas palavras de Schudson (2003, p.84), a objetividade contribui para proteger o campo de interferências externas. É o primeiro valor que se mobiliza para garantir a independência das redações em relação aos interesses comerciais - a "muralha da China" que deve existir entre aqueles que fornecem as informações e aqueles que vendem espaço na mídia. É a bandeira que os profissionais erguem para se defender das pressões ligadas aos interesses políticos ou econômicos dos patrões. É o sustentáculo da legitimidade construída diante do público consumidor de informações (GANS, 2004 [1979], p. 186).

A noção de objetividade permanece, também, como um recurso para avaliar se o jornalismo "cumpre seu papel" em sociedades orientadas pelos valores liberais. O entendimento de que a imprensa atua como instituição política, tomando para si funções de governo (COOK, 2005 [1998]), assim como sua caracterização em diferentes momentos históricos como um "quarto poder", pressupõe o vínculo entre atuação política e autonomia. Seu poder depende do "poder da objetividade" que corresponde, por sua vez, à exclusão explícita dos valores, ignorando as implicações da cobertura e colocando em suspenso os pontos de vista dos próprios jornalistas (COOK, 2005 [1998], p.90). A imprensa está a serviço dos cidadãos e ocupa legitimamente a função de expor os abusos do poder quando age de maneira autônoma em relação aos interesses existentes e às pressões da autoridade política constituída e é, portanto, capaz de fornecer informações objetivas. Estas não se confundem nem com os interesses de governos, partidos e outras instituições políticas nem com o autointeresse de empresas e dos próprios jornalistas. $\mathrm{O}$ jornalismo fiel ao público e à democracia é um espelho fiel da realidade.

É esse o entendimento que baliza, por exemplo, as avaliações realizadas pelos "observatórios de imprensa" ou pelos ombudsmen dos jornais. O funcionamento do jornalismo - e sua contribuição para a democracia - é avaliado por seu grau de aproximação com o ideal da objetividade, isto é, pelo desvio ou cumprimento de uma norma compartilhada que pressupõe que o bom jornalismo corresponde à difusão de informações verdadeiras ${ }^{4}$. Faz parte desse registro a distinção entre jornalismo factual e jornalismo opinativo, ou entre conteúdo factual e opinativo dentro dos mesmos veículos. Mesmo quando se afasta das posições mais ingênuas, a distinção entre o factual e o opinativo atualiza um dos pilares do ideal da objetividade, o entendimento de que é possível ou normativamente desejável produzir informações que estariam desvinculadas das opiniões ou perspectivas sociais dos jornalistas.

É preciso, nesse sentido, distinguir entre a crítica que denuncia a falta de objetividade (como um desvio, considerando que o jornalismo não só deveria, mas poderia ser objetivo de fato), a crítica que se ancora no valor da objetividade, mas entende que é impossível cumpri-lo (a objetividade é mantida como valor de referência, mesmo sendo impossível atingi-la) e a crítica que entende que o jornalismo não deve ser objetivo, isto é, que a objetividade não é um ideal normativo adequado. A separação entre jornalismo factual e jornalismo opinativo parece situar-se no segundo desses registros. Deglutida a crítica ao jornalismo como espelho fiel da realidade, sustenta que existe uma verdade não perspectiva que deve ser o ideal almejado pelo jornalismo.

Essas análises, no entanto, voltam-se para o que pode ser considerado um segundo nível de

\footnotetext{
${ }^{4}$ Para um exemplo excepcionalmente ingênuo desta postura, ver Marcelino et al (2009).
} 
construção dos discursos. É nesse nível que os rituais da objetividade se materializam em procedimentos como o recurso equilibrado às fontes, permitindo que "os dois lados" da notícia se pronunciem, a ausência de adjetivação e a utilização de aspas (TUCHMAN, 1972), demarcando a heterogeneidade entre o autor e as fontes de informação (AUTHIER-REVUZ, 1990). Quando a análise se volta para esse nível, concentra-se no que é contingente nos discursos. São considerados os textos que surgem e são substituídos por outros rapidamente, em uma dinâmica rotineira em que as enunciações se sucedem, deixando de lado sua relação necessária com discursos que têm maior permanência e que estão em sua base (como na noção de comentário em Foucault, 1996 [1971], p.22·26).

Os discursos factuais atualizam, rotineiramente, discursos valorativos. E esses últimos estão na base dos procedimentos de seleção e destaque de que são feitos os primeiros. Antes de serem assumidos pelo noticiário, implícita ou explicitamente, os valores são parte da própria definição do que é notícia (GANS, 2004 [1979], p.41). Mas o ponto central para esta discussão é que o noticiário é organizado por valores e preconceitos a partir dos quais os fatos ganham saliência e transformam-se em notícias, inseridos em narrativas causais. Dizendo de outra forma, as informações fazem sentido se e apenas se têm como pano de fundo discursos mais permanentes, valorativos. A colaboração entre jornalistas e fontes tem, assim, uma faceta menos explícita, a do acordo tácito quanto aos valores e aos limites da política. Os atores políticos antecipam o que é capaz de atrair os jornalistas, enquanto estes últimos antecipam as reações das suas fontes às histórias noticiadas, em uma dinâmica que ressalta a colaboração entre o jornalismo e a política e favorece determinadas abordagens (COOK, 2005 [1998], p.91).

Os fatos ganham sentido em um complexo "sistema de diferenças" (MANIN, 1997, p.227), no qual algumas imagens, representações e valores destacam-se em relação a outros. Mas o texto jornalístico, ancorado no ideal da objetividade e na valorização de uma posição imparcial, nega que "o significado de cada termo seja o resultado da coexistência de vários termos distintos uns dos outros" (MANIN, 1997, p.227). Este autor recorre a essa imagem, inspirada na explicação saussuriana do funcionamento dos sistemas linguísticos, para definir as campanhas eleitorais como processos opositivos, nos quais diversas imagens chocam-se umas com as outras definindo as identidades dos atores em disputa.

É possível traçar um paralelo com a produção do noticiário. A seleção dos fatos, com sua disposição em narrativas específicas, é sempre alternativa, isto é, realiza-se em detrimento de outros fatos e narrativas possíveis. A seleção dos fatos jornalísticos (desdobramentos de eventos, atores e enunciados que Ihes dão "carne") consiste na saliência de alguns em relação a outros. E essa saliência é, por sua vez, ancorada na força que alguns discursos valorativos adquiriram, socialmente, em relação a outros. O efeito de realidade produzido pela correção e adequação dos procedimentos de captura e produção da notícia apaga o fato de que ela toma forma em um contexto de disputas e sobreposições entre complexos distintos de valor, cristalizados em discursos. Nesse sentido, a verdade pode ser entendida como o resultado de um "trabalho moral" que forja um consenso, permitindo que os julgamentos apareçam como fatos (ETTEMA e GLASSER, 1998, p.62). 


\section{O observador intocável}

Nos depoimentos de jornalistas estadunidenses colhidos por Gans, aparece com frequência a ideia de que os profissionais do jornalismo seriam capazes de colocar-se acima dos conflitos sociais e políticos. Acima, mas não fora deles. A proximidade não-participante, o testemunho sem tomada de partido, é que confere valor ao relato do jornalista. As imagens do "observador intocável" e do "estranho invisível" (SCHORR apud GANS, 2004 [1979], p. 185) são parte do ethos da profissão.

No Brasil, a normatização da profissão e os entendimentos sobre o papel do jornalista a partir da década de 1940 destacaram a relação entre disponibilidade, testemunho diferenciado e distanciamento. Definições presentes nos primeiros compêndios normativos e nos depoimentos de jornalistas que participaram das transformações da imprensa brasileira em meados do século XX teriam eco nas décadas posteriores, fornecendo referenciais para a identificação e valorização dos jornalistas. Imagem frequente nesses discursos, o jornalista full time reúne disponibilidade e observação diferenciada. Foi definido pelo jornalista Alberto Dines como um "servidor público" que, atento, "ensina a sociedade a pensar", sem fornecer "juízo feito", "pré-juízos ou pré-conceitos". A imprensa, por sua vez, cumpre seu papel, segundo Dines, quando é equilibrada e politizada (no sentido de ter visões abrangentes sobre a política) sem ser o "reflexo de uma posição política" ou partidária (ABREU, LATTMAN-WELTMAN e ROCHA, 2003, p.156).

Suspensas suas posições políticas - e também o que é específico de sua posição social - e guiando-se por critérios profissionais de relevância, o jornalista seria capaz de produzir informações objetivas e imparciais. O fato de que não correspondam à realidade, mas a uma realidade, como dito anteriormente, não impede que essas informações sejam assim definidas. A objetividade e a imparcialidade são, nesse caso, o oposto ao viés e à expressão de posições, mesmo não correspondendo à expressão de toda a realidade. O noticiário resulta de escolhas, mas estas remetem ao ambiente profissional, com seus imperativos, e não ao indivíduo com suas inclinações (GANS, 2004 [1979], p.203). A adesão aos critérios jornalísticos para a seleção e construção da notícia, por outro lado, não precisa ser sofisticada do ponto de vista técnico. A formação técnica não é condição necessária para o domínio dos critérios que definem os valores-notícia e os padrões aceitos para o texto jornalístico em um dado contexto. O profissionalismo corresponde, nesta análise, sobretudo ao compartilhamento de valores, normas e rotinas, assim como à participação em hierarquias específicas. Corresponde, ainda, ao reconhecimento de uma competência profissional diferenciada pelos pares e pelos leigos, independentemente de ter sido produzida pelo acesso ao conhecimento formalizado, transmitido pelas faculdades de jornalismo, ou pelo cotidiano de trabalho.

A objetividade está na base dessa distinção entre profissionais e leigos no campo jornalístico. Os padrões e rituais que denotam o cumprimento desse ideal normativo sustentam a credibilidade do jornalismo diante do público. Pode-se dizer que isso se dá porque jornalistas e público compartilham a compreensão de que o bom jornalismo, aquele que merece crédito, é objetivo e imparcial. Quando são vistos como objetivos, isto é, capazes de fornecer informações verdadeiras a partir das quais o público formaria seu julgamento, os jornalistas estão protegidos da desconfiança quanto aos critérios 
BIROLI, F.; MIGUEL, L. F. Orgulho e preconceito: a "objetividade" como mediadora...

mobilizados para a construção da notícia (GANS, 2004 [1979], p.186). A defesa da objetividade funciona, também, como um modo de isolar a atividade jornalística da influência de interesses que, pela via do poder político ou do poder econômico, tentariam subjugá-la. Mas isso não significa que os jornalistas se coloquem, idealmente, em uma posição "desinteressada". Eles seriam, diferentemente, capazes de vocalizar o interesse da totalidade, acima dos interesses parciais. É algo que estava presente já no início do século XX, no pensamento de Lippmann, seguramente o autor singular que mais impacto teve na formulação da ideologia do jornalismo estadunidense. Ele combinava uma defesa do jornalismo "objetivo" com a ideia de que era tarefa dos jornalistas contribuir para "fazer os negócios públicos andarem melhor" (LIPPMANN, 1997 [1922], p.251).

Em outras palavras, os observadores intocáveis seriam também intocados, isto é, libertos do autointeresse e da parcialidade que caracteriza os atores políticos e os cidadãos comuns que formam seu público. Isso não os levaria a pensar da posição de ninguém, mas da posição de todos, produzida a partir do acesso privilegiado à totalidade. Entre os jornalistas, a objetividade significaria, ao mesmo tempo, a possibilidade de colocar-se acima dos conflitos sociais e políticos e a presunção de que seus valores seriam universais e dominantes (GANS, 2004 [1979], p.185-6). O afastamento da própria individualidade e das perspectivas e crenças que a definem não levaria à ausência de valores, mas à mobilização de valores tidos como universais e, como tal, justos. Os valores que estão na base da seleção e compreensão dos fatos seriam os valores do público. E não seriam, portanto, objeto de conflito ou disputa. A objetividade é, portanto, efeito de duas fiç̧̃̃es simultâneas: a suspensão do jornalista como indivíduo socialmente posicionado e a transformação do público em coletivo moral homogêneo.

Valores dominantes e duradouros estão na base dos critérios de relevância assumidos pelos jornalistas. Consistem, como se disse antes, no primeiro nível de construção dos discursos. O segundo nível, no qual se encontram as marcas discursivas dos procedimentos e rituais que garantiriam a objetividade, deve seu sentido àquele. É por isso que seu caráter valorativo não entra em conflito com a objetividade. Pelo contrário, torna-a possível (GANS, 2004 [1979], p.196-7). Assumidos como reflexos de julgamentos exteriores e compartilhados pelo público, os julgamentos presentes no noticiário representam concepções que se impõem como consensuais. Nessa dinâmica, o discurso jornalístico é validado por um senso comum que ele mesmo colabora para formatar. E é, em última instância, legitimado pelas relações de poder que ele colabora para naturalizar.

Nos espaços caracterizados como opinativos, os julgamentos explicitados refletiriam aqueles já sustentados pelo público (GANS, 2004 [1979], p.198). Esse argumento silencia sobre o fato de que os jornalistas e os meios de comunicação têm um papel na conformação do ambiente político e dos valores compartilhados pelo público. Sem inflar a importância da mídia na construção simbólica do mundo social, sua especificidade em relação a outras instituições que participam dessa construção estaria justamente no fato de que confere um "certificado de importância legítima" àquilo que noticia e a quem faz parte do noticiário (SCHUDSON, 2003, p.33). Outro aspecto silenciado nesse argumento é o poder das fontes e das hierarquias vigentes em outros campos sociais, que são respaldadas pelo jornalismo ${ }^{5}$. A

\footnotetext{
${ }^{5}$ Para análises empíricas que demonstram a acomodação do jornalismo brasileiro às hierarquias vigentes no campo político, ver Gomes (2008).
} 
acomodação do jornalismo às estruturas de poder resulta, simultaneamente, de estruturas organizacionais e tradições culturais específicas, que constituem a "etiqueta da profissão" (SCHUDSON, 2003, p.13), e da capacidade diferenciada que os atores externos à redação têm para se impor e tomar parte na rotina jornalística (GANS, 2004; COOK, 2005 [1998]). A complementaridade entre essas duas dinâmicas tem peso na definição de quais serão os valores sustentados pelo jornalismo objetivo.

\section{0 guardião dos valores}

Assim como os julgamentos se transmutam em fatos, no jornalismo a pluralidade e a heterogeneidade social se transformam na oposição entre valores legítimos e atores (ou comportamentos) desviantes. O sentido da objetividade não se restringe à correspondência entre fatos $\mathrm{e}$ realidade externa. Inclui, também, a correspondência entre fatos e julgamentos que expressam valores supostamente universais. O engajamento dos jornalistas com esses valores, isto é, com os valores assim reconhecidos, não entra em confronto com o ideal da objetividade. Por isso, podem alegar que confrontam as realidades do vício e da virtude sem recorrer a um senso moral próprio, transformando conhecimento social objetivo em discurso (ETTEMA e GLASSER, 1998, p.7). O julgamento jornalístico, e não o julgamento moral, mediaria a relação dos jornalistas com a realidade social. Com isso, seriam capazes de transformar "apelos morais em apelos empíricos de modo que os padrões de julgamento utilizados para avaliar a transgressão sejam vistos como tão empiricamente isentos de ambiguidades quanto as evidências utilizadas para documentar sua existência" (ETTEMA e GLASSER, 1998, p.71). Nessa lógica, "a ordem moral é transformada em fato e o fato pode ser reportado com distanciamento" (ETTEMA e GLASSER, 1998, p.71).

A objetividade resultaria, assim, de acordos quanto aos valores que constituem as premissas dos julgamentos, e não da suspensão desses julgamentos (ETTEMA e GLASSER, 1998, p.61). Denúncias, acusações e a vilanização de atores e instituições contribuem para que os acordos sejam reafirmados sem que seja necessário defendê-los de um modo que exponha seu conflito com valores diferentes daqueles que estão na base do noticiário.

A noção de acordo aqui utilizada remete ao funcionamento concreto da mídia, à posição social que os jornalistas de fato ocupam e ao perfil de seu público. A aceitação de um ponto de vista como universal está fundada em uma relação específica entre jornalistas e público. Dotado do diferencial da competência técnica e da ética profissional que o credenciam para relatar fidedignamente a realidade, o jornalista dilui-se, no entanto, na universalidade que é comum com seus leitores, ouvintes ou espectadores.

Há ainda, nesta relação, as representações que os jornalistas fazem de seu público, em grande medida compartilhadas em seu ambiente profissional. Em alguns casos, a similaridade entre a posição socioeconômica dos jornalistas e do seu público permite o compartilhamento de perspectivas e interesses - no Brasil, essa similaridade pode ser considerada, por exemplo, na análise das revistas semanais de informação. Por outro lado, a dependência cognitiva do público em relação à mídia leva a compreensões comuns, entre público e jornalistas, do que é relevante em um dado momento e contexto, 
de quais são as clivagens que permitem entender as disputas e de quem são os atores que se destacam. Nesse aspecto, as posições socioeconômicas não parecem ser adequadas para a construção de hipóteses sobre a conformação de um senso comum compartilhado. A centralidade da televisão para a sociabilidade contemporânea, por exemplo, desdobra-se num repertório comum que, embora ressignificado pelos receptores, pode sobrepor-se à heterogeneidade das experiências dos indivíduos e às diferenças estruturais entre os grupos sociais.

Assim, o jornalismo objetivo e imparcial mobiliza valores que, de modo geral, não são reconhecidos como tal. Mas, quando os julgamentos emergem e são assim caracterizados, são apresentados como o reflexo de valores compartilhados. É em nome da "decência", por exemplo, que as acusações são dirigidas aos funcionários ou políticos corruptos. É em nome do "bom senso" que o desperdício de recursos é exposto.

Nesse quadro, a avaliação do papel do jornalismo na conformação dos valores hegemônicos varia. A ênfase pode estar nos atores políticos e econômicos poderosos, que teriam suas posições e interesses legitimados e reforçados pelo jornalismo. Nesse caso, a análise das visões de mundo que se impõem destaca o papel das fontes e das hierarquias fora das redações (GANS, 2004). Pode estar, também, na relação entre cultura jornalística e cultura política, que forjariam em conjunto valores duradouros. Nesse caso, a complementaridade vem do fato de as práticas jornalísticas serem o produto de um ambiente social específico (SCHUDSON, 2003). A ênfase pode recair, ainda, sobre os próprios jornalistas, ressaltando sua atuação no sentido de forjar os consensos. Aqui, destaca-se o "trabalho moral" realizado pelos jornalistas, especialmente por se entender que o consenso que está na base dos julgamentos por eles mobilizados não é, em momento algum, estável ou completo (ETTEMA e GLASSER, 1998, p.62).

A especificidade da mídia, dentre outras instituições, pode ser entendida, como se disse antes, como a capacidade de legitimar determinadas representações da realidade social. Quando consideramos que não existe um discurso hegemônico estável e estruturado de maneira permanente, o trabalho cotidiano dos jornalistas é o de lapidar consensos. Essa lapidação pode corresponder à acomodação dos conflitos entre segmentos (ou classes) sociais diferentes em representações do "bem comum". Isto é, à sua organização em uma gramática moral comum que neutraliza os conflitos. E o jornalismo pode, também, e concomitantemente, assumir o papel de árbitro nas disputas entre as elites políticas. Nesse caso, o trabalho consistiria em atribuir significados ao comportamento dos atores e ao funcionamento das instituições, colando a eles julgamentos que exibem, diante do público, seu grau de adequação às práticas que seriam incontestavelmente adequadas e aos valores tidos como universais.

\section{O enigma de Veja}

O ideal da objetividade e a afirmação dos valores morais não são excludentes. Pelo contrário, sua reciprocidade é necessária para a legitimação simultânea das práticas jornalísticas e de julgamentos que derivam de um ambiente social específico. Mas o jornalismo não funciona como um espelho ou uma lente refratora. Ele colabora, ativamente, para a conformação dos valores e perspectivas socialmente 
hegemônicos.

As formas que assume variam de uma correspondência mais estrita das práticas e do discurso aos cânones da objetividade até o rompimento com esses cânones, sem romper, no entanto, com as ficções mencionadas antes: a suspensão do jornalista como indivíduo socialmente posicionado e a transformação do público em coletivo moral homogêneo. Os julgamentos, que podem orientar o noticiário factual ou tomar o seu lugar, continuam a ter sua legitimidade sustentada pelo entendimento de que são expressivos de valores morais não conflitivos ou previamente assumidos pelo público. Nesse sentido, pode-se dizer que a objetividade canônica é abandonada, sem que se abandone o ideal de um jornalismo que não toma partido e é capaz de afastar-se dos interesses e perspectivas parciais.

O jornalismo da revista Veja expõe essa dinâmica, exemplificando a tensão e a acomodação simultâneas entre objetividade, imparcialidade e discurso valorativo. É capaz de romper com os cânones da objetividade jornalística e, ao mesmo tempo, manter a aderência de leitores que não precisaram desatar a conexão entre bom jornalismo, verdade e imparcialidade para continuarem a recorrer a Veja para se informar. Para analisá-lo, vamos focar em duas reportagens de capa que lidam com o "risco" de que, com a vitória de um candidato petista - antes Lula, agora Dilma Rousseff -, os setores "extremistas" do partido ganhem força para implementar suas ideias. Em 23 de outubro de 2002, portanto, às vésperas do segundo turno da eleição presidencial, a revista mostrava na capa um cérebro com as cabeças hidrófobas de Lênin, Trótski e Marx e a chamada "O que querem os radicais do PT".

$\mathrm{Na}$ edição de 14 de julho de 2010, portanto, logo no início da campanha oficial para o primeiro turno, a capa apresentava concepção bastante similar. A ilustração da capa, reproduzida com pequenas alterações no miolo, mostra uma hidra vermelha de cinco cabeças, com uma estrela desbotada ao fundo. A chamada não deixa lugar a dúvidas: "O monstro do radicalismo: a fera petista que Lula domou agora desafia a candidata Dilma". O gancho da reportagem é o imbróglio envolvendo o programa de governo de Dilma Rousseff - a versão inicialmente depositada junto à Justiça Eleitoral, considerada muito radical, foi substituída pelo PT.

Dentro, a matéria, assinada por Otávio Cabral, é intitulada "A criatura contra-ataca". As cinco cabeças da hidra correspondem às propostas "extremistas": punição de torturadores, imposto sobre grandes fortunas, legalização do aborto e o que Veja chama de "controle da imprensa" e de "salvo. conduto para o MST" (exigência de negociação com os sem-terra, antes da reintegração de posse de áreas ocupadas). Todo o conhecimento que o leitor tem do documento provém das interpretações fornecidas pela reportagem, uma vez que a revista não reproduz uma única linha do texto original.

Este é um dos mecanismos mais evidentes de produção de sentido, em que a autoria do jornalista e a edição do texto sobrepõem-se aos documentos e depoimentos que seriam a base do texto jornalístico. Um dos pontos mais batidos pela Veja é chamado de "controle da imprensa" (p.64, p.68), ataque às "garantias à liberdade de expressão" (p.65), "tentativa de cercear a liberdade de imprensa" (p.67), "controle estatal da imprensa" (p.68) e "controle da imprensa livre" (p.69). O conteúdo das medidas propostas é explicado em poucas linhas: "Dar ao governo condições para interferir na programação, no gerenciamento e na propriedade das emissoras de rádio e TV" (p.64). Os defensores da proposta, porém, falam em "democratização" dos meios de comunicação, com a quebra dos monopólios 
privados e a ampliação da pluralidade de vozes com acesso à mídia.

Este discurso não aparece em Veja. O único entrevistado sobre o tema é Daniel Slaviero, presidente da Associação Brasileira de Emissoras de Rádio e Televisão (Abert), a entidade que reúne os proprietários da mídia, que vê a medida como a brecha "para que se intervenha e censure um veículo de comunicação" (p.68). Estamos a anos-luz da regra de "ouvir os dois lados", que Tuchman apresenta como central nos rituais da objetividade jornalística. Os defensores do controle social da mídia não têm voz; o documento entregue pelo PT à Justiça Eleitoral não é citado; e mesmo as explicações da coordenação da campanha de Dilma Rousseff para a confusão com os programas de governo são abertamente ridicularizadas:

\begin{abstract}
"Sem sucesso no governo Lula, a tentação autoritária estaria rondando agora a campanha de Dilma Rousseff? Segundo os petistas, não. Tudo não passou de um erro grotesco, uma trapalhada. A campanha da ex-ministra é a mais bem organizada, conta com uma equipe enorme de advogados, assessores, jornalistas, marqueteiros e políticos experientes. Porém, teria sido apenas na manhã de segunda-feira passada, o prazo final para o registro das candidaturas no Tribunal Superior Eleitoral, que alguém percebeu que faltava um documento obrigatório a ser encaminhado à Justiça - o programa de governo. Parece inacreditável, mas ninguém sabia onde estava o programa de governo da candidata" (p.67).
\end{abstract}

Nos últimos anos, a "liberdade de imprensa" tem sido uma bandeira constante nas páginas de Veja. Entre 2007 e 2009, a revista dedicou 11 reportagens ao tema. Apenas como comparação, no mesmo período, entre as suas concorrentes, Época publicou duas reportagens sobre liberdade de imprensa, ao passo que IstoÉ e CartaCapital não publicaram nenhuma ${ }^{6}$. Em Veja, o tema pode servir apenas como pretexto para mais uma diatribe contra o presidente venezuelano Hugo Chávez (Duda Teixeira, "O coronel agora é censor", Veja, 31/1/2007, p.83) ou para comemorar a extinção da Lei de Imprensa herdada da ditadura militar (Diego Escosteguy, "Um fóssil se vai", Veja, 6/5/2009, p.120). Mas cada uma dessas matérias contribui para compor um quadro nítido: a oposição entre o modelo de livre mercado, propugnado pela revista, e os defensores de formas autoritárias de controle da informação. Neste segundo grupo, ao lado da ditadura de 1964 e de Hugo Chávez, quando não de Cuba e da Coreia do Norte, estão os setores da esquerda que defendem a democratização dos meios e as iniciativas do governo Lula, como a abortada tentativa de criação do Conselho Federal de Jornalismo, em 2004, ou a realização da Conferência Nacional de Comunicação, em 2009.

Mesmo as críticas de Lula à cobertura da mídia são apresentadas como sintomas de uma tentação autoritária. "Por onde se olha na América Latina, há um governante com a ideia fixa de que

\footnotetext{
${ }^{6}$ Em sua edição 606, de 28 de julho de 2010 CartaCapital finalmente dedicou-se ao tema. A reportagem de capa, intitulada "Censura: um fantasma apenas", dedicava-se a mostrar que a liberdade de imprensa não se encontra em risco no Brasil. É evidente o intuito de se contrapor ao discurso de Veja. No relato de CartaCapital, as "propostas equivocadas e, em geral, inócuas encampadas por setores do governo" não têm peso para merecer o status de ameaças à liberdade de imprensa. Mas a reportagem entrevista tanto porta-vozes das empresas quanto defensores do "controle social da mídia" (Sergio Lirio, "Fantasmas à solta", CartaCapital, 28/7/2010, p.20-5).
} 
seus fracassos seriam menos gritantes se só existisse a imprensa oficial. O Brasil vinha sendo a excepcionalidade na região. Agora o próprio presidente Lula está desenhando o que ele imagina ser a imprensa ideal", diz uma reportagem não assinada ("Más notícias, presidente", Veja, 4/11/2009, p.100). O problema é a intolerância às críticas: "A imprensa livre é um estorvo em PTópolis. Ela insiste em investigar, fiscalizar e dar nome aos bois". Na mesma reportagem, a menção a um discurso em que Lula teria dito aos jornalistas para construir suas matérias a partir da experiência dos catadores de papel, recomendando que as publicassem sem interpretar, é seguida dos seguintes comentários: "É espantoso. Lula não lê jornais. Mas quer ensinar como editar jornais. Má notícia, senhor presidente. Ter $80 \%$ de popularidade não credencia ninguém a ser repórter ou editor".

Ettema e Glasser observam o papel da ironia na produção do lugar de "guardião da consciência moral" que o jornalismo se atribui. Ela permite apresentar um julgamento moral sem que seja necessário fazer um "sermão" sobre o tema (ETTEMA e GLASSER, 1998, p.87). Ao mesmo tempo, a ironia estabelece uma cumplicidade entre o texto e seu leitor. Para que funcione, para que seja decodificada de forma adequada, ela exige um vocabulário moral compartilhado (ETTEMA e GLASSER, 1998, p.105).

Trata-se de uma ferramenta comum no repertório do jornalismo. Mas o uso que Veja faz dela merece atenção. Na matéria sobre o programa de governo de Dilma Rousseff, a galhofa é contida, como uma piscadela ao leitor: será mesmo que uma campanha tão bem organizada se atrapalharia na entrega da documentação à Justiça Eleitoral? A dúvida ajuda a construir o argumento subjacente, de que os petistas radicais não estão tão domesticados quanto os líderes do partido gostam de anunciar, e ainda têm força suficiente para emplacar, mesmo que só por algumas horas, o programa oficial da candidata. Há, também, uma sobreposição entre a ironia e o recurso às aspas, que é parte importante dos procedimentos-rituais da objetividade e da marcação da exterioridade entre os enunciados assumidos pelo autor e aqueles atribuídos a outrem. Um exemplo é a legenda que acompanha a imagem da hidra no miolo da matéria - "As propostas que entraram "por engano'” ·, em que a expressão "por engano" aparece entre aspas e em vermelho, destacada das palavras que a precedem sem aspas e em cinza.

O sarcasmo pesado da matéria sobre as críticas de Lula à imprensa, incomum no jornalismo fora dos espaços de "opinião", é de outra natureza. Marca uma identidade de oposição ao governo, que a própria reportagem apresenta como sendo própria do bom exercício profissional: "Não existe jornalismo a favor" ("Más notícias, presidente", Veja, 4/11/2009, p.100). Mas a oposição específica ao governo Lula é diluída na caracterização supostamente inconteste do papel da imprensa e dos limites dos governos para sua regulação. Esse papel seria regido, ao mesmo tempo, por normas jurídicas e valores compartilhados, o que leva a revista a sustentar que "os próprios leitores e a Justiça punem os jornalistas que ultrapassam os limites éticos".

A crítica ao desempenho da mídia é automaticamente igualada ao anseio por controlá-la, em outro importante estratagema de produção de sentido por parte de Veja. Para um exemplo significativo, é possível voltar à reportagem de 14 de julho de 2010, sobre os riscos do radicalismo na candidatura de Dilma Rousseff. O título da capa não deixa dúvidas sobre quem é a hidra: "O monstro do radicalismo". O olho da matéria, porém, diz que a questão é se Dilma Rousseff conseguirá "domar o monstro do autoritarismo" (p.65). E o terceiro parágrafo do texto assinala que "Dilma está sendo desafiada pelo 
BIROLI, F.; MIGUEL, L. F. Orgulho e preconceito: a "objetividade" como mediadora...

monstro do atraso com suas múltiplas cabeças ágrafas, ignorantes, passadistas e liberticidas" (p.65). 0 monstro é, simultaneamente, o radicalismo, o autoritarismo e o atraso. No discurso de Veja, os três substantivos contam como sinônimos. Os radicais tentam impor visões minoritárias, portanto, são autoritários. E não percebem que suas doutrinas foram superadas pela história, portanto, são atrasados.

O deslizamento promove a equivalência entre radical e autoritário, radical e atrasado, sem que seja necessário aduzir uma única justificativa. O que torna possível tal manobra - e que faz com que ela seja encarada com total naturalidade; na verdade, com que não seja sequer percebida - é o fato de que a revista e seus leitores compartilham de um mesmo universo mental, no qual a modernidade (o oposto do atraso) e a democracia (o oposto do autoritarismo) correspondem aos países capitalistas centrais, nos quais, por sua vez, todo o jogo político se dá sob o signo da moderação (o oposto do radicalismo). Qualquer ideia que fuja da conformidade com um modelo, aliás bastante estrito, de ordenamento econômico e político liberal é "radical”, logo, atrasada e autoritária. Qualquer inconformidade com o padrão dado de gestão dos meios de comunicação de massa é censura. Emparelhadas com vocábulos de claro sentido pejorativo, tais propostas não merecem ser ouvidas em seus próprios termos (afinal, quem precisa de defensores da censura ou da ditadura na mídia?) e podem receber a condenação moral que merecem.

A isenção, portanto, não é uma suspensão de julgamento. Mas não admite a contestabilidade da norma que está na base desse julgamento. É, portanto, o julgamento objetivo, isto é, ancorado em fatos, com base em uma norma igualmente objetiva, isto é, entendida como pertencendo à natureza das coisas. Assim considerado, o transgressor é um transgressor, e nomeá-lo como tal não representa uma ruptura, mas a confirmação da isenção jornalística.

A transformação dos julgamentos em fatos não corresponde, como tal, ao falseamento de informações em sentido estrito. Mas abre brechas para informações que são imprecisas, porém, coerentes com os discursos sustentados. Na matéria sobre o programa de governo de Dilma Rousseff, o leitor de Veja não teve acesso aos programas registrados, apenas aos comentários da revista. Em um pequeno quadro, sob o título "O que ficou", Veja informa seu leitor de que "Apesar de alterado, o item que trata da liberdade de imprensa ainda defende o controle da mídia" (Otávio Cabral, "A criatura contra- ataca", p.65). No programa de governo registrado no TSE, no entanto, não há qualquer passagem que corresponda à defesa do controle da mídia ou mesmo um item que trate especificamente da liberdade de imprensa. Nos trechos que podem ter levado a esse julgamento, o programa define as "cadeias de rádio e de televisão" como "pouco afeitas à qualidade, ao pluralismo, ao debate democrático"; fala em "monopólio e concentração dos meios de comunicação" e associa o aprofundamento da democracia brasileira a uma "forte circulação de ideias" (Coligação para o Brasil seguir Mudando, “Diretrizes do Programa 2011/2014", itens 42.44, p.15).

Interpretações que anulam o fato, ironia e o jogo das equivalências (e mesmo a provisão de informações imprecisas) são os instrumentos principais por meio dos quais a revista produz sentido. Sem a adesão a um conjunto de códigos compartilhado com seus leitores, porém, pode-se supor que haveria resistência a tomadas de partido tão indisfarçadas. A eficácia desses instrumentos depende da cumplicidade com o público. É de se perguntar, então, como Veja foi capaz de se colocar nesta posição 
de garantir uma cumplicidade tão extensa entre seus preconceitos e os de seus leitores. É isso que parece permitir que a revista rompa com os cânones da objetividade e explicite seu engajamento com determinados valores de modo mais acentuado do que a média da mídia brasileira, sem, no entanto, comprometer sua posição de destaque nesse campo e a credibilidade diante do público.

Trata-se de algo que foi construído ao longo dos anos. A cumplicidade pode ser explicada, ao mesmo tempo, pela identidade entre a posição social dos jornalistas e dos leitores e pela posição que a mídia e, nesse caso, a revista Veja especificamente, têm na conformação dos valores compartilhados pelos leitores e do senso comum, em sentido mais amplo. A reportagem de 2002 sobre os radicais possui pontos de contato, mas também diferenças marcadas em relação à sua similar de oito anos mais tarde. Em primeiro lugar, ela é muito mais informativa, no sentido que o jornalismo atribui à palavra. Veja procura sustentar a importância das correntes "radicais" dentro do PT, apontando quantos filiados cada uma delas agregaria, quais são suas principais lideranças e que propostas defendem (box "As tendências do PT", p.40-1). Ainda que haja ironia - a ideologia da corrente Articulação de Esquerda é identificada como "marxista de manual" -, há também alguma explicação de suas ideias. Assim, para a tendência O Trabalho, o orçamento participativo, "em vez de fomentar o crescimento de organizações populares independentes, resulta em sua cooptação pelo aparelho de Estado".

Também são entrevistados líderes da esquerda petista, com destaque para a senadora Heloísa Helena, que merece um pingue-pongue reproduzido num box da matéria ("O discurso light do PT me irrita", p.42-4). Outros entrevistados são o ex-prefeito de Porto Alegre, Raul Pont; os deputados federais eleitos Ivan Valente e Luciana Genro; e Marcus Sokol, da corrente O Trabalho. São reproduzidos trechos de documentos das tendências de esquerda. Não é que falte um julgamento explícito, por vezes marcado pela ironia e sempre denunciando as propostas radicais como uma ameaça às liberdades e ao bem-estar do povo brasileiro:

\footnotetext{
“Defendem a 'expropriação do patrimônio da grande burguesia', a reestatização de empresas privatizadas, o amordaçamento da imprensa (sob o eufemismo de "controle social dos meios de comunicação"). Em outras palavras, querem que sejam impostas ao país medidas anacrônicas e tão factíveis quanto convencer o ditador cubano Fidel Castro a cortar sua barba" (p.38).
}

A denúncia, porém, é apoiada em extratos do discurso dos próprios radicais, que a evidenciariam. Assim, Heloísa Helena manifesta seu desgosto com a moderação do discurso petista, Ivan Valente, Luciana Genro e Marcus Sokol pregam o rompimento com o Fundo Monetário Internacional. A visão de Genro sobre a situação da Colômbia é tachada de "completamente desprovida de sentido de realidade", mas a revista não se furta a citar seu argumento de que há "uma intervenção político-militar do imperalismo contra as Farc, principal expressão da luta dos camponeses" (p.44). Os enquadramentos preferidos da esquerda do PT são desqualificados de forma expressa no texto, mas não estão completamente ausentes - ao contrário do que ocorre na edição de 2010. Nesta, os petistas, "radicais" ou não, são mencionados sem voz. A matéria contrapõe "petistas moderados" - como Antonio Palocci, "o 
fiador da estabilidade econômica", Luiz Dulci, "responsável pela relação amistosa com os movimentos sociais", e Fernando Pimentel (sem maiores explicações) - a "figuras antagônicas", entre as quais estão Franklin Martins, "defensor do controle da imprensa livre", Paulo Vannuchi, "o mentor do Programa Nacional de Direitos Humanos", e Marco Aurélio Garcia, "a voz mais estridente de um grupo numeroso, embora minoritário, que habita uma das áreas mais pantanosas do PT". Não se considerou necessário explicar que áreas são essas.

Nos oito anos do governo Lula, portanto, Veja aprofundou seu afastamento em relação aos cânones da objetividade ostensiva, assumindo - de maneira ainda mais aberta - um tom antipetista militante. Por outro lado, ao adotar uma postura incisiva de condenação a políticos de oposição envolvidos em escândalos (como na cobertura do esquema de corrupção envolvendo o então governador do Distrito Federal, José Roberto Arruda, em 2009 e 2010), a revista atestava sua neutralidade quanto às consequências do noticiário, um dos componentes da própria objetividade. O jornalista objetivo não deve considerar os efeitos daquilo que reporta, deve ser despreocupado quanto a quem se beneficiará e quem será prejudicado com a notícia veiculada (GANS, 2004, p.188). A notícia é justa, portanto, quando são justas suas intenções, que não remeteriam senão aos próprios critérios jornalísticos. Os efeitos não pretendidos não entram no cálculo de justiça. Os transgressores, sejam eles quais forem, não são alvos de um jornalista ou de um veículo, mas do bom senso e dos critérios morais socialmente compartilhados.

O recurso à neutralidade permite a Veja manter-se como "objetiva" (no sentido de reportar a realidade tal como é) e "partidária", no sentido amplo da palavra. É conhecido o comentário de Gramsci, para quem "um jornal (ou um grupo de jornais), uma revista (ou um grupo de revistas) são também 'partidos', 'frações de partido' ou 'funções de determinados partidos'” (GRAMSCI, 2000 [1933-5], p.350). Incorporando um projeto político, Veja cumpre funções de partido; fazendo dele não uma opção, mas um imperativo moral, impede que seu discurso seja entendido como parcial; denunciando e condenando políticos partidários do mesmo projeto, afirma-se como neutra.

Nas narrativas sobre a história da imprensa, o jornalismo objetivo é apresentado em oposição ao jornalismo partidário. Enquanto este último, financiado por interesses políticos, é um instrumento de propaganda, o jornalismo objetivo é abrigado em empresas comerciais que visam o lucro, mas é capaz de mobilizar seus próprios valores normativos para escapar de pressões indevidas. A concorrência mercantil aparece, então, como instrumento importante de manutenção da autonomia do campo jornalístico, uma vez que o público consumidor puniria os veículos que se rendessem à manipulação da informação ${ }^{7}$.

O problema do jornalismo partidário, porém, parece ser menos o risco de manipulação do que a ausência de neutralidade. Schudson define assim a diferença entre jornalismo "objetivo" e jornalismo "partidário":

"A norma de objetividade leva os jornalistas a separar fatos de valores e a noticiar apenas

\footnotetext{
7 O "caso Mark Willes" - o executivo do Los Angeles Times que, nos anos 1990, tentou subverter as normas da ética jornalística para ampliar o retorno econômico e perdeu o cargo diante da resistência de repórteres e leitores - é o exemplo mais citado (cf. Janeway, 1999, p. 151).
} 
OPINIÃO PÚBLICA, Campinas, vol. 18, n 1, Junho, 2012, p. 22 - 43

os fatos. Espera-se que o tom da reportagem objetiva seja frio, em vez de emotivo. A reportagem objetiva cuida para representar, de forma justa, cada um dos lados principais numa controvérsia política. De acordo com a norma de objetividade, o trabalho do jornalista consiste em reportar algo chamado "notícia" sem comentá-la, enviesá-la ou conformar sua formulação de qualquer maneira. O valor da objetividade é afirmado especificamente contra o jornalismo partidário, no qual os jornais são os aliados declarados ou agentes de partidos políticos e suas 'notícias' são um elemento da luta partidária. Jornalistas partidários, tal como jornalistas objetivos, tipicamente rejeitam inexatidão, mentira e desinformação, mas não hesitam em apresentar a informação da perspectiva de um partido ou facção em particular" (SCHUDSON, 2001, p.150).

Também no Brasil, é frequente entre jornalistas e estudiosos o entendimento de que o "lento desengajamento partidário dos jornais" permitiu que a cobertura política se adequasse ao "modelo da imparcialidade e da isenção" (CORRÊA, 2002, p.259). Em registro semelhante, entende-se que o jornalismo brasileiro teria se modernizado, a exemplo do norte-americano, passando de combativo a informativo e sendo capaz de separar "o comentário pessoal da transmissão objetiva e impessoal da informação" (ABREU, 2002, p.15).

Podemos voltar à definição de Gramsci para ressaltar a função partidária da imprensa. Não se trata, aqui, de validar o modelo que essas narrativas consideram historicamente ultrapassado, o da vinculação entre veículos de imprensa e partidos políticos específicos, mas de colocar em questão a oposição mais abrangente entre partidarismo e neutralidade, entre o jornalismo dependente do patrocínio dos políticos e o jornalismo orientado pela lógica empresarial. Uma primeira forma de confrontá-la é expor os laços entre a mídia empresarial e o campo da política. A substituição do jornalismo "patrocinado" pelo jornalismo "subsidiado" daria conta de maneira mais realista desse processo e do padrão daí resultante, que envolve relações e determinações recíprocas entre um modo de organização da política liberal e um modo de organização do jornalismo moderno (COOK, 2005[1998]). Mas é preciso ressaltar a autonomia relativa em relação aos governos e partidos políticos, sem confundi. la com imparcialidade e isenção. Essa autonomia permite, entre outras coisas, transformar a ideia de que o jornalismo é capaz de espelhar a realidade sem reproduzir as posições parciais em um recurso para intervir, em nome do bem comum e de valores universais, nas disputas entre segmentos das elites políticas.

No sentido aqui trabalhado, o jornalismo objetivo não deixou de ocupar a função de partido, mesmo que não se vincule a um partido político: representa interesses e perspectivas sociais específicos, estabelece mediações entre as instituições políticas e os cidadãos, procura impor visões de mundo e forjar consensos. Ele colabora para a reprodução de valores socialmente hegemônicos ao silenciar sobre as disputas em torno desses valores. Mas esse silêncio não significa a ausência de posições ou a acomodação a posições prévias, anteriores e exteriores. Ao apresentar julgamentos como fatos, o jornalismo participa ativamente da construção dos próprios fatos. Atua politicamente quando atribui significados às disputas presentes. E atua com maior eficácia quando, respaldado pelos ideais da 
objetividade e da imparcialidade, articula perspectivas e interesses parciais em discursos identificados como neutros e não posicionados.

\section{Conclusões}

No jornalismo, a neutralidade corresponde à validação de discursos hegemônicos. 0 entendimento de que veículos e jornalistas mantêm posição de exterioridade em relação aos conflitos políticos e sociais Ihes confere a possibilidade de colocar em circulação julgamentos, sem a pecha de agir em nome de interesses específicos. Quando a neutralidade é considerada um ideal que não se efetiva, mas que permite distinguir entre o bom jornalismo e o ruim, a oposição entre fatos e julgamentos permanece ainda como uma referência para jornalistas, público e analistas.

A ambição de produzir um discurso que espelhe a realidade é central ao ideal da objetividade, mas não esgota seus sentidos. O papel ativo dos jornalistas na seleção dos aspectos da realidade que ganham relevância no noticiário é, há muito tempo, considerado também por aqueles que mantêm a neutralidade como um ideal. Os discursos mais ingênuos sobre a correspondência entre jornalismo e "fatos" são pouco frequentes. Mas fica mantida a ideia de que, se não é possível dar conta de toda a realidade, seria possível ao menos colocar em suspenso os julgamentos. A verdade seria alcançada quando (e porque) é possível assumir uma posição imparcial. Mantém sua força, também, o entendimento de que os julgamentos presentes no noticiário, quando são assim reconhecidos, correspondem a valores sociais compartilhados e não conflitivos. Seriam, assim, a expressão da opinião pública, codificada como bom senso informado. Julgar não seria, nesse sentido, tomar partido.

A realidade que o discurso jornalístico apresenta é um artefato moral. Mas como as disputas entre interesses e representações diversas do mundo social não são explicitadas, ela é apresentada como um artefato sem artífices. O ideal da objetividade não corresponde apenas à ilusão de que os jornalistas podem transcender sua condição de indivíduos socialmente posicionados. Corresponde, também, à ficção de que os valores morais hegemônicos são universais. Objetividade e imparcialidade são, nesse sentido, dispositivos que permitem ocultar o trabalho moral realizado pelos jornalistas.

$\mathrm{Na}$ base dos framings presentes no noticiário estão valores relacionados a posições e interesses sociais específicos, a partir dos quais os fatos jornalísticos tomam forma. Em outras palavras, a matéria dos fatos são os julgamentos, e não o contrário. Naturalizados e objetivados, os padrões de valores assumidos pelo jornalismo são a base para posições que não aparecem como tomada de partido, mas como a expressão da própria realidade. Os fatos noticiados demonstrariam, sem a necessidade de interpretações, o apego ou o desvio de atores e instituições a códigos tomados como óbvios. Veículos e jornalistas podem, assim, julgar instituições e indivíduos mantendo-se dentro dos limites do que é entendido como seu papel: o de críticos imparciais. Expressam posições políticas e valorativas específicas que são, no entanto, apresentadas como a expressão de uma crítica que resguarda valores que seriam os de "todos nós".

Considerando que a neutralidade dissimula valores e envolvimentos, o jornalismo não pode ser tomado como simples veículo dos discursos e interesses hegemônicos. Mais do que colocá-los em 
circulação, o jornalismo participa de sua afirmação, sobretudo por sua capacidade de legitimar e naturalizar determinadas compreensões da realidade. Atua em contextos marcados por conflitos e disputas horizontais e verticais. Representa "valores comuns" em sociedades estruturalmente marcadas por relações de poder assimétricas, traduzidas em vantagens e desvantagens para parcelas diferentes da população. Transcende, supostamente, os conflitos em contextos marcados por disputas entre elites políticas. Dissimula, portanto, o fato de ser um ator político e funcionar, nesse sentido, como partido . independentemente de sua relação com partidos políticos específicos.

O ideal da objetividade e a afirmação dos valores morais não são excludentes. É mesmo o contrário disso: "fatos objetivos" e julgamentos complementam-se na legitimação do jornalismo como guardião dos valores sociais. Essa dinâmica parece estar presente, com variações, nas dimensões da ética e das práticas que organizam o jornalismo nas sociedades liberais contemporâneas. A análise da revista semanal brasileira Veja permitiu destacar um aspecto central à sua sustentação: 0 compartilhamento dos valores entre o jornalismo e seu público. A dependência cognitiva do público em relação aos meios de comunicação e o baixo grau de pluralidade desses últimos são variáveis importantes nessa relação. Consideradas, impedem uma simplificação: a ideia de que a percepção clara de posições e interesses por parte do público orientaria a escolha de um veículo de informação, que atuaria então como representante de um segmento específico da população. O equívoco, nesse caso, está em tomar o vínculo entre os veículos de comunicação e seu público como a mera formalização de posições e entendimentos que o antecederiam. Trata-se, diferentemente, de uma relação complexa e que se estende no tempo, na qual as representações da realidade social são alimentadas por um noticiário factual que é, por sua vez, resultante de representações específicas dessa mesma realidade. A neutralidade é, portanto, o efeito de parcialidades que coincidem ou se assemelham em contextos nos quais o jornalismo tem uma atuação importante na lapidação dos consensos.

\section{Referências Bibliográficas}

ABREU, A. A. de. A modernização da imprensa. Rio de Janeiro: Jorge Zahar, 2002.

ABREU, A. A. de; LATTMAN-WELTMAN, F.; ROCHA, D. (orgs.). Eles mudaram a imprensa: depoimentos ao CPDOC. Rio de Janeiro: Editora FGV, 2003.

ALBUQUERQUE, A.; SOARES, R. F. "Notícias de notícias: Notícias do Planalto, memória e autoridade jornalística". Comunicação \& Política, v. XI, n. 1, p. 135-69, 2004.

AUTHIER-REVUZ, J. “Heterogeneidade(s) enunciativa(s)”. Caderno de Estudos Linguísticos, n. 19, p. 25-42, 1990.

BOUDANA, S. "On the values guiding the French practice of journalism: interviews with thirteen war correspondents". Journalism, v. 11, n. 3, p. 293-310, 2010.

BOURDIEU, P. The political field, the social science field, and the journalistic field, In: BENSON, R.; NEVEU, E. (eds.). Bourdieu and the journalistic field. Cambridge: Polity, 2005 [1995].

CARPENTIER, N. "Identity, contingency and rigidity: the (counter)hegemonic constructions of the identity of the media professional". Journalism, v. 6, n. 2, p. 199-219, 2005. 
BIROLI, F.; MIGUEL, L. F. Orgulho e preconceito: a "objetividade" como mediadora...

CARPENTIER, N.; TRIOEN, M. "The particularity of objectivity: a post-structuralist and pshicoanalytical reading of the gap between objectivity-as-a-value and objectivity-as-a-practice in the 2003 Iraq War coverage". Journalism, v. 11, n. 3, p.311-28, 2010

COOK, T. E. Governing with the news: the news media as a political institution. 2.ed. Chicago, London: The University of Chicago Press, 2005 [1998].

CORRÊA, V. Conversa com a memória: a história de meio século de jornalismo público. Rio de Janeiro: Objetiva, 2002.

DEUZE, M. "What is journalism? Professional identity and ideology of journalists reconsidered". Journalism, v. 6, n. 4, p.442.64, 2005

ETTEMA, J. S.; GLASSER, T. L. Custodians of conscience: investigative journalism and public virtue. New York: Columbia University Press, 1998.

FOUCAULT, M. A ordem do discurso. São Paulo: Loyola, 1996 [1971].

FSB COMUNICAÇÕES. Mídia e política: pesquisa sobre os hábitos de informação dos deputados federais. Brasília: FSB Comunicações, 2009.

GANS, H. J. Deciding what's news: a study of CBS Evening News, NBC Nighlty News, Newsweek, and Time. Evanston: Northwestern University Press, 2004 [1979].

GOMES, W. "Mapeando a audioesfera política brasileira: os soundbites políticos no Jornal Nacional". XVII ENCONTRO DA COMPÓS, 2008, PUC.SP, São Paulo.

GRAMSCI, A. Caderno 17 (1933-1935). In: GRAMSCI, A. Cadernos do cárcere. Rio de Janeiro: Civilização Brasileira, v. 3 2000 [1933-5].

JANEWAY, M. Republic of denial: press, politics, and public life. New Haven: Yale University Press, 1999.

LIPPMANN, W. Public opinion. New York: The Free Press, 1997 [1922].

MANIN, B. The principles of representative government. Cambridge: Cambridge University Press, 1997.

MARCELINO, D. et al. "A cabeça do jornalista: opiniões e valores políticos dos jornalistas no Brasil". Comunicação \& Política, v. 27, n. 3, p. 13.42, 2009.

MIGUEL, L. F. e COUTINHO, A. A. "A crise e suas fronteiras: oito meses de 'mensalão' nos editoriais de jornais”. Opinião Pública, v.13, n.1, 2007.

O ESTADO DE S. PAULO. Manual de redação e estilo. Organizado e editado por Eduardo Martins. São Paulo: O Estado de S. Paulo, 1990.

SCHUDSON, M. "The objectivity norm in American journalism". Journalism, v. 2, n. 2, p. 149.70, 2001.

The sociology of news. New York: Norton, 2003.

TUCHMAN, G. "Objectivity as strategic ritual: an examination of newsmen's notions of objectivity". American Journal of Sociology, v. 77, n. 4, p. 660.79, 1972.

WAISBORD, S. Watchdog journalism in South America: news, accountability and democracy. New York: Columbia University Press, 2000.

Flávia Biroli · fbiroli@terra.com.br

Luis Felipe Miguel · Ifelipemiguel@uol.com.br

Recebido para publicação em setembro de 2010.

Aprovado para publicação em agosto de 2011. 